\title{
TREATMENT OF T3a BLADDER CANCER WITH IRIDIUM IMPLANTATION
}

\author{
H. BARTON GROSSMAN, M.D. \\ HOWARD M. SANDLER, M.D. \\ CLAUDIA PEREZ-TAMAYO, M.D.
}

From the Department of Surgery, Section of Urology, and the Department of Radiation Oncology, University of Michigan, Ann Arbor, Michigan

\begin{abstract}
A total of 7 patients with high grade, T3a (Stage B2) bladder cancer were treated with external radiation therapy and interstitial iridium implantation from May 1986 through March 1988. Follow-up has ranged from nineteen to sixty-one months with a median of forty months. One patient has required a cystectomy and is currently free of disease, and 1 patient has had recurrence of his cancer and metastatic carcinoma has developed; 5 are free of disease and have maintained their usual state of bladder function. Iridium implantation maintains bladder function and is effective therapy for selected individuals with localized, muscle-invading bladder cancer.
\end{abstract}

Muscle-invasive bladder cancer continues to be a therapeutic challenge because currently available treatment modalities produce less than optimal quantity as well as quality of life. The goals of preserving both life and bladder function frequently conflict in patients with invasive bladder cancer. Aggressive local therapy directed toward the primary disease while preserving a functional bladder is a strategy that fulfills both treatment goals. A variety of therapeutic approaches have been employed to achieve these objectives. Highly selected Stage T2 (B1) bladder tumors can be adequately treated with transurethral resection alone. ${ }^{1}$ Other reports have documented the beneficial results of partial cystectomy and brachytherapy for more invasive tumors. ${ }^{2.3}$ In 1986, we began a clinical trial of external beam radiotherapy along with interstitial iridium $\left.{ }^{192} \mathrm{Ir}\right)$ implantation in patients with localized, deeply invasive bladder cancer. This report describes our initial experience with ${ }^{192} \mathrm{Ir}$ brachytherapy in patients with localized T3a (B2) bladder cancer.

\section{Material and Methods}

From May 1986 through March 1988, 7 patients with T3a transitional cell carcinoma of the bladder were treated with external beam radiotherapy followed by interstitial implantation using ${ }^{192} \mathrm{Ir}$. All tumors were grade 2 or 3 using the World Health Organization classification (grades 1-3). One tumor involved the left ureteral orifice causing eversion of this structure into a volcano-type configuration. This tumor was muscle invasive and is included as a T3a neoplasm. However, it does not readily fit the American Joint Committee staging system (third edition) and could arguably be classified a T2 neoplasm. All patients had local lesions 5 $\mathrm{cm}$ or less with no evidence of other bladder abnormality as documented by random biopsy specimens. The mean age was sixty-nine years (range 57-78). There were two women and five men. Three patients had prior superficial bladder malignancies which were treated endoscopically. Two of these had prior intravesical chemotherapy: 1 patient had BCG and the other was treated with thiotepa followed by doxorubicin.

Prior to implantation, the patients were treated with external beam therapy to a median dose of $45 \mathrm{~Gy}$ (range was 35-46 Gy). Pelvic lymphadenectomy and interstitial implantation were performed an average of twenty-three 
days (range 9-39 days) after completion of the planned external beam radiation. A pelvic lymphadenectomy was performed followed by the implantation. No patient had detectable lymphatic metastasis. A cystotomy was made and the periphery of the tumor was marked with gold seeds. Hollow plastic tubes were placed through $14 \mathrm{~g}$ needles in a parallel fashion through the detrusor at the site of the tumor bed. The needles were removed and dummy iridium wires were placed through the afterloading tubes. The cystotomy was closed, and the catheter ends were brought directly out through the cystotomy and the skin incision.

The patients were brought to the Department of Radiation Oncology where orthogonal radiographs were performed with the dummy seeds in place. The dose distribution was calculated for the actual seed locations and the patient was appropriately afterloaded in their hospital room.

The seed strength averaged $0.58 \mathrm{mCi}$ (range $0.52-0.62 \mathrm{mCi})$. A single plane implant was used with three to five catheters, each catheter containing four to nine seeds. The catheters were spaced at $1.2 \mathrm{~cm}$ intervals. The average implant dose was 19.26 Gy (range 15.15-22.75 $\mathrm{Gy}$ ), and this was delivered at $0.30-0.65 \mathrm{~Gy} / \mathrm{hr}$. The iridium wires and afterloading catheters were removed at the patient's bedside.

Patient follow-up ranges from nineteen to sixty-one months, with a median of forty months from the start of preoperative radiotherapy. Routine evaluation included cystoscopy, urine cytology, and excretory urography (IVP).

\section{Results}

The location of the bladder tumors is illustrated in Figure 1. Three of the tumors were either on or immediately adjacent to the trigone. The incidence and time of local failure are depicted in Figure 2. Two of the 7 patients have had bladder tumor recurrences. In 1 patient multifocal bladder carcinoma developed four months after initiation of therapy. Squamous cell carcinoma was present adjacent to the implanted field and carcinoma in situ occurred distant from the implantation site. He subsequently was treated with radical cystectomy and is free of disease nineteen months following the start of his treatment. In the other patient a tumor recurrence developed ouside the implantation field ten months following the start of preoperative radiotherapy and he was

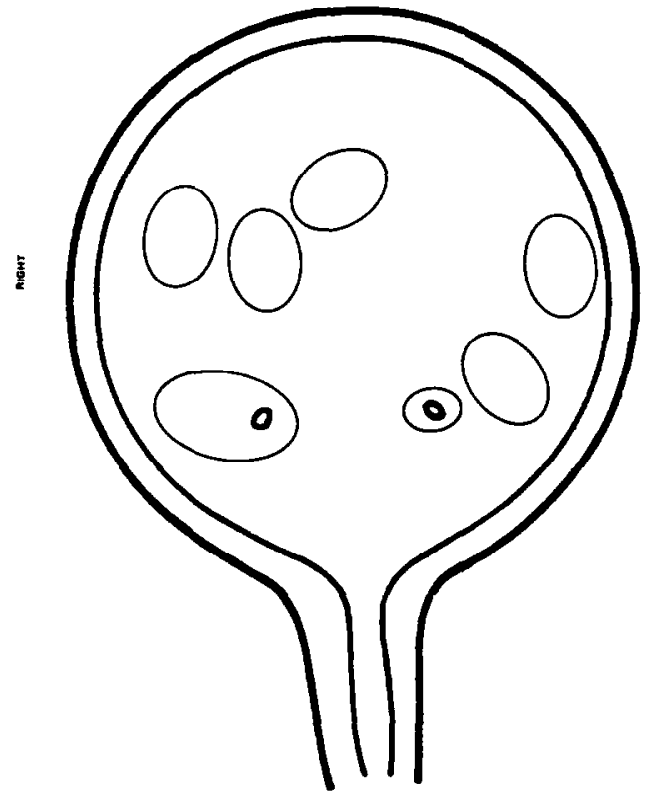

FiguRE 1. Location of bladder tumors treated by iridium implantation.

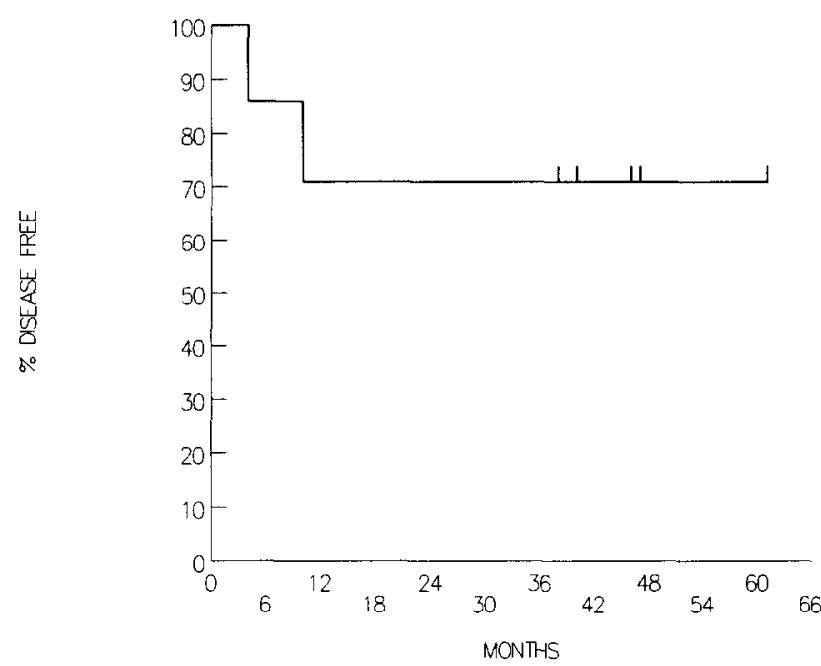

FIGURE 2. Time to disease recurrence. All patients are currently alive. Patient who failed at four months was salvaged with cystectomy and is diseasefree nineteen months from initiation of preoperative radiotherapy. Patient who failed at ten months is alive with metastatic bladder cancer thirty-one months after start of treatment.

treated with intravesical mitomycin. Transitional cell carcinoma of the prostate with metastatic disease developed twenty-six months following the start of his treatment. He had a partial response to chemotherapy (M-VAC) and is currently alive with local and metastatic disease thirty-one months after treatment initiation. The remaining 5 patients are alive and free of bladder cancer thirty-eight to sixty-one 
months following the initiation of therapy. In 1 of these patients poorly differentiated large cell lung cancer has developed with metastasis related to this second primary disease.

Toxicity has been acceptable with no longterm bladder toxicity attributable to the radiation. Three patients have had immediate and delayed postoperative complications. One patient had prolonged urinary drainage from the implant site that lasted one month. This resolved without further therapy. The second patient had a history of severe peripheral vascular disease and had a wound dehiscence and pulmonary embolus postoperatively. The third patient had a history of colectomy for adenocarcinoma of the colon five years prior to his implant. Significant diarrhea occurred following his preoperative radiation which promptly resolved with only an occasional loose stool. However, a small-bowel obstruction developed requiring surgical therapy five months following his implant. His bladder cancer recurred and progressed resulting in voiding problems related to the extensive urothelial carcinoma in his prostate.

\section{Comment}

The most common approach for the treatment of muscle-invasive bladder cancer in the United States is radical cystectomy. The advantage of this approach is that it removes the primary tumor with wide margins and simultaneously treats other recognized or nonrecognized, multifocal neoplasia within the bladder. The eradication of locally invasive cancer while preserving normal bladder function can be accomplished provided that (1) appropriate patients are selected for treatment and (2) the therapy is effective in eliminating the neoplasm but still preserves overall bladder function. Both of these criteria must be met for patients to have effective cancer therapy while retaining normal micturition. The most important aspect of this is patient selection. Patients who do well with less than total removal of their bladders usually have focal, invasive disease with the remainder of their bladder being free of neoplasm. Muscle-invasive disease has been adequately treated in highly selected patients by transurethral resection of $\mathrm{T} 2$ neoplasms and segmental resection of T2 and T3a tumors. ${ }^{1,2}$ Transurethral resection is usually limited to highly selected patients with T2 disease. Similarly, segmental resection requires the ability to obtain an adequate resection margin.
TABLE I. Local recurrence rate after brachytherapy of bladder cancer

\begin{tabular}{|c|c|c|c|c|}
\hline Series & Implant & Stage & $\begin{array}{c}\text { No. } \\
\text { of } \\
\text { Pts. }\end{array}$ & $\begin{array}{c}\text { Local } \\
\text { Recurrence } \\
\text { Rate }(\%)\end{array}$ \\
\hline van der Werf-Messing ${ }^{3}$ & Radium & $\begin{array}{l}\mathrm{T} 2 \\
\mathrm{~T} 3\end{array}$ & $\begin{array}{r}328 \\
63\end{array}$ & $\begin{array}{l}16 \\
28\end{array}$ \\
\hline $\begin{array}{l}\text { Batterman }{ }^{4} \\
\text { van der Werf-Messing }\end{array}$ & $\begin{array}{l}\text { Radium } \\
\text { Cesium }\end{array}$ & $\begin{array}{l}\mathrm{T} 2 \\
\mathrm{~T} 2 \\
\mathrm{~T} 3\end{array}$ & $\begin{array}{l}85 \\
48 \\
42\end{array}$ & $\begin{array}{l}19 \\
12 \\
14\end{array}$ \\
\hline $\begin{array}{l}\text { Straus }^{7} \\
\text { Mazeron }^{8}\end{array}$ & $\begin{array}{c}\text { Iridium } \\
\text { Iridium and } \\
\text { part. cyst. }{ }^{*}\end{array}$ & $\begin{array}{c}\text { T2-3a } \\
\text { T2 } \\
\text { T3 }\end{array}$ & $\begin{array}{r}11 \\
30 \\
5\end{array}$ & $\begin{array}{r}18 \\
7 \\
0\end{array}$ \\
\hline
\end{tabular}

*Partial cystectomy.

This makes segmental resection relatively easy when localized, muscle-invading tumors occur in the bladder dome but more difficult in other areas of the bladder.

Brachytherapy, the use of radiotherapy over short distances by interstitial implantation, has also been effectively employed in the treatment of bladder cancer (Table I). The obvious advantage of this approach involves the ability to give high doses of radiation to a small treatment area while the surrounding area receives relatively little radiation. van der Werf-Messing and associates ${ }^{3}$ have a large experience with the use of radium implantation in bladder cancer. They reported on a series of 328 patients with T2 and 63 patients with T3 bladder cancer treated with preoperative radiation (3 times 3.5 Gy) followed by radium implantation. Some patients received a lower dose of brachytherapy supplemented with postoperative radiation (30 $\mathrm{Gy})$. The overall five-year survival for $\mathrm{T} 2$ and T3 tumors was 56 and 37 percent, respectively. The actuarial survival corrected for non-cancer related death was 75 and 62 percent, respectively. The incidence of local recurrence at five years for patients with T2 and T3 tumors was 16 and 28 percent, respectively. The survival and incidence of local recurrence for patients with T3a and T3b tumors was similar.

Battermann and Tierie ${ }^{4}$ employed a similar technique $(3 \times 3.5 \mathrm{~Gy}$ preoperatively followed by radium implantation). The local control rate for T2 tumors was 81 percent $(69 / 85)$. The actuarial ten-year survival and ten-year diseasefree survival was 34 and 56 percent, respectively.

Other isotopes have also been employed for brachytherapy of invasive bladder cancer. Williams and associates ${ }^{5}$ reported on the use of either ${ }^{198} \mathrm{Au}$ or ${ }^{182} \mathrm{Ta}$ implants. The five-year 
survival using ${ }^{198} \mathrm{Au}$ implantation in 53 patients with T2 and 18 patients with T3 bladder cancer was 35 and 24 percent, respectively. The same survival data when ${ }^{182} \mathrm{Ta}$ was employed in $23 \mathrm{~T} 2$ and 6 T3 tumors was 55 and 0 percent, respectively.

Van der Werf-Messing and van Putten ${ }^{6}$ employed $40 \mathrm{~Gy}$ external radiation followed by ${ }^{137} \mathrm{Cs}$ implantation in 48 patients with $\mathrm{T} 2$ and 42 patients with T3 bladder cancer. The actuarial uncorrected and disease-specific fiveyear survival was approximately 70 and 80 percent for patients of either stage. Straus and associates reported on the use of preoperative irradiation (10-15 Gy for tumors less than $3 \mathrm{~cm}$ and 36-50 Gy for tumors $3-5 \mathrm{~cm}$ ) and ${ }^{102} \mathrm{Ir}$ implantation with an afterloading technique. ${ }^{7}$ Eleven patients with T2-T3a tumors were treated. The actuarial survival at twenty-four months was 72 percent. Mazeron and associates $^{8}$ employed a combination of preoperative radiation (8.5 Gy in a single fraction), partial cystectomy, and iridium implantation adjacent to the resection margin. Thirty $\mathrm{T} 2$ and five $\mathrm{T} 3$ tumors were treated. The disease-free and cause-specific survival of 20 patients with T2 disease followed for five years was 55 and 73 percent, respectively. One of 4 patients with T3 bladder cancer who had been followed for five years was alive and free of disease.

We initiated our investigation of iridium implantation of invasive bladder cancer based on the favorable experience of van der Werf-Messing and her colleagues in Rotterdam. Our selection of patients for this treatment has been rigorous and only included individuals who had muscle-invading tumors without concurrent evidence of multifocal neoplasia. All tumors were less than $5 \mathrm{~cm}$ in size. However, tumor site was not a factor in selection. Five of 7 patients are alive, without bladder cancer, and with their bladder intact for a period of thirty-eight to sixty-one months following their implantation. An additional patient is alive and diseasefree following a salvage cystectomy. Although more patients and increased follow-up are required to determine the true significance of these preliminary results, they compare favorably to the results obtained with radical cystectomy. ${ }^{9}$ Our limited experience with iridium implantation provides additional evidence that brachytherapy is effective treatment for focal high-grade, high-stage bladder cancer while preserving normal voiding function in the majority of patients.

1500 E. Medical Center Drive Ann Arbor, Michigan 48109-0330

(DR. GROSSMAN)

\section{References}

1. Herr HW: Conservative management of muscle-infiltrative bladder cancer: prospective experience, J Urol 138: 1162 (1987).

2. Novick A, and Stewart BH: Partial cystectomy in the treatment of primary and secondary carcinoma of the bladder, J Urol 116: 570 (1976).

3. van der Werf-Messing B, Menon RS, and Hop WCJ: Cancer of the urinary bladder category $\mathrm{T} 2, \mathrm{~T} 3$, (NxMo) treated by interstitial radium implant: second report, Int J Radiat Oncol Biol Phys 9: 481 (1983).

4. Battermann JJ, and Tierie AH: Results of implantation for T1 and T2 bladder tumours, Radiother Oncol 5: 85 (1986).

5. Williams GB, Trott PA, and Bloom HJG: Carcinoma of the bladder treated by interstitial irradiation, $\mathrm{Br} \mathrm{J}$ Urol 53: 221 (1981).

6. van der Werf-Messing BHP, and van Putten WLJ: Carcinoma of the urinary bladder category $\mathrm{T} 2,3 \mathrm{NxMo}$ treated by 40 Gy external irradiation followed by cesium ${ }^{137}$ implant at reduced dose (50\%), Int I Radiat Oncol Biol Phys 16: 369 (1989).

7. Straus KL, et al: Treatment of bladder cancer with interstitial iridium-192 implantation and external beam irradiation, Int J Radiat Oncol Biol Phys 14: 265 (1988).

8. Mazeron J-J, etal: Conservative treatment of bladder carcinoma by partial cystectomy and interstitial iridium 192, Int J Radiat Oncol Biol Phys 15: 1323 (1988).

9. Brendler CB, et al: Local recurrence and survival following nerve-sparing radical cystoprostatectomy, J Urol 144: 1137 (1990). 